\title{
Escrever como atriz, como mulher
} Writing as an actress, as a woman

Iassanã Martins ${ }^{1}$

Patrícia Fagundes ${ }^{2}$ 


\section{Resumo}

O artigo discute aspectos de uma escrita feminista desenvolvida durante $o$ processo de criação cênica e escrita do memorial crítico-reflexivo Todas Nós: Atuação cênica e Práticas de intimidade. A partir do olhar da atriz e seus questionamentos sobre sua própria prática, sua escrita e referências de artistas mulheres, propõe-se uma reflexão crítica sobre as estruturas que se apresentam naturalizadas e que inserem um modo específico de pensar e narrar o nosso campo, artes cênicas em diálogo com o mundo.

Palavras-chave: Teatro; teatro feminista; atuação; atriz; escrita feminista

\section{Abstract}

The article highlights aspects of a feminist writing developed during the process of theatrical and written creation of the critical-reflexive memorial Todas Nós: Atuação cênica e Práticas de intimidade. From the perspective of the actress who questions her own practice, her own writing and her references of female artists, the article proposes a critical reflection on the structures that are naturalized and that insert a specific way of thinking and narrating our field, the performing arts in dialogue with the world.

Keywords: Theater; feminist theater; acting; actress; feminist writing

ISSN: 1414.5731

E-ISSN: 2358.6958

\footnotetext{
${ }^{1}$ Doutoranda pelo Programa de Pós-Graduação em Artes Cênicas - Universidade Federal do Rio Grande do Sul (UFRGS. iassana.teatro@gmail.com

${ }^{2}$ Profa. Dra. Adjunta Departamento de Arte Dramática e Programa de Pós-Graduação em Artes Cênicas - Universidade Federal do Rio Grande do Sul (UFRGS). Diretora da Cia Rústica de Teatro (Porto Alegre). patfag26@hotmail.com
} 
O teatro se relaciona, provoca e denuncia aspectos que emergem em sua época. Nesse sentido, os assuntos relacionados a gênero e feminismos são imprescindíveis e não poderiam deixar de ser um tema da cena contemporânea. Neste texto, apresentamos os atravessamentos de um pensamento e de uma escrita feminista que surgiu e se desenvolveu no processo de criação cênica de Todas Nós, analisado no memorial crítico-reflexivo intitulado Todas Nós: Atuação cênica e práticas de intimidade, defendido em 2017, no Programa de Pós-Graduação em Artes Cênicas da Universidade Federal do Rio Grande do Sul, sob orientação da Profa. Dra. Patricia Fagundes.

Iniciar uma pesquisa, e um processo de criação cênica, é lançar-se por caminhos nebulosos. O desejo e o medo do desconhecido andam lado a lado. Iniciamos em parceria - mestranda e orientadora - um trabalho que se propunha investigar uma atuação a partir da noção de "práticas de intimidade", unindo referências da pesquisa Práticas de Encontro: o político na cena contemporânea 3 com o conceito articulado por Óscar Cornago, no qual propõe a intimidade como um eixo das práticas cênicas contemporâneas, provocando questões além da dicotomia público-privado: "A intimidade se faz, não se representa, [...] e este fazer, que é um fazer originalmente entre vários, dá lugar a uma situação íntima, uma experiência associada a esse fazer, que transforma temporalmente o espaço em que ocorre" (Cornago, 2011, p. 447).

Assim, o termo "práticas de intimidade" define a busca de possibilidades de criação entre as participantes do evento cênico, compartilhando atmosferas que se desenvolvem através de um jogo que se propõe a estar junto, olho no olho, exigindo despojamento na atuação. Sem muitos efeitos e renunciando ao fascínio de uma dimensão espetacular grandiosa, esse tipo de prática expõe seus mecanismos e reivindica o exercício de criação compartilhada. Um modo de fazer associado ao aqui e agora, na partilha de um momento que se faz na relação de confiança estabelecida entre atriz e espectadora.

O memorial-crítico reflexivo exige dois trabalhos que se concretizam em conjunto: criação cênica e texto escrito. As duas etapas acontecem conjuntamente, uma retroalimenta a outra. Por isso, foi preciso passar por um processo de criação cênica que se fez escrita na carne e no papel, e que foi construído em primeira pessoa por se tratar de um processo criativo de uma atriz que estava pensando sua prática. Deste modo, a partir de agora este texto também se apresenta em primeira pessoa por revelar aspectos de um memorial construído a partir da perspectiva e experiência da atriz e pesquisadora.

\section{O trabalho da atriz}

É preciso situar o contexto histórico: 2015, indícios de um impeachment que se concretiza no ano seguinte. Uma mulher, Dilma Rousseff, é afastada por um GOLPE4

\footnotetext{
${ }^{3} \mathrm{O}$ grupo de pesquisa tem como objetivo investigar aspectos relacionais do teatro como microterritórios de sociabilidade, através da conexão entre teorias e práticas, no qual o fazer artístico é vinculado à experiência estética, ética e política. Coordenado pela Prof. ${ }^{a}$ Dr. $^{a}$ Patricia Fagundes, com a participação de alunos de mestrado e graduação.

${ }^{4}$ Golpe de Estado articulado pelo vice-presidente Michel Temer juntamente com outros parlamentares - deputados e senadores - profundamente envolvidos em casos de corrupção instituíram um processo de destituição contra a presidenta pretextando irregularidades contabilísticas, "pedaladas fiscais", para cobrir défices nas contas públicas - uma prática corriqueira em todos os governos anteriores, inclusive pelos deputados de direita que conduziram a campanha contra a presidente são uns dos mais comprometidos nesse caso, começando pelo presidente da Câmara dos Deputados, Eduardo Cunha, que foi preso no dia 19/10/2016, acusado de corrupção, lavagem de dinheiro e evasão fiscal. Artigos sobre a cassação e prisão de Eduardo Cunha disponíveis em: https://brasil.elpais.com/brasil/2017/03/30/politica/1490887717_318231.html. https:/www.correiobraziliense.com.br/app/noticia/politica/2018/06/01/interna_politica,685540/eduardo-cunha-e-condenado-a-28-anos-de-prisao.shtml Acesso em 30 de outubro de 2018. Artigo sobre Michel Temer sobre crime de obstrução à justiça, disponivel em: https:// brasil.elpais.com/brasil/2017/06/27/politica/1498518532_904635.html. Acesso em 30 de outubro de 2018.
} 
orquestrado por políticos envolvidos em caso de corrupção. No livro Porque gritamos golpe?: Para entender o impeachment e a política no Brasil, diversas autoras e autores registram sob seu ponto de vista dinâmicas sobre o impeachment contra a Presidenta Dilma Rouseff situando este fato em nosso país. No capítulo intitulado Da tragédia à farsa: o golpe de 2016 no Brasil, Michael Löwy (2016) afirma que a destituição da presidenta eleita foi um golpe de estado. Fala também que os parlamentares que conduziram a campanha contra a presidenta são uns dos mais comprometidos em caso de corrupção.

O golpe de Estado parlamentar de maio de 2016 é uma farsa, um caso tragicômico, em que se vê uma cambada de parlamentares reacionários e notoriamente corruptos derrubar uma presidente democraticamente eleita por 54 milhões de brasileiros, em nome de "irregularidades contábeis". O principal componente dessa aliança de partidos de direita é o bloco parlamentar (não partidário) conhecido como "a bancada BBB": da "Bala" (deputados ligados à Polícia Militar, aos esquadrões da morte e às milícias privadas), do "Boi" (grandes proprietários de terra, criadores de gado) e da "Bíblia" (neopentecostais integristas, homofóbicos e misóginos). Entre os partidários mais empolgados com a destituição de Dilma destaca-se o deputado Jair Bolsonaro (PP), que dedicou seu voto pela abertura do processo de impeachment na Câmara aos oficiais da ditadura militar, nomeadamente ao coronel Brilhante Ustra, um torturador notório. (Uma das vítimas de Ustra foi Dilma Rousseff, que no início dos anos 1970 era militante de um grupo de resistência armada, e também meu amigo Luiz Eduardo Merlino, jornalista e revolucionário, morto em 1971 sob tortura, aos 21 anos de idade.) O presidente interino, Michel Temer, entronizado por seus acólitos, está envolvido em vários casos suspeitos. Uma pesquisa recente perguntou aos brasileiros se votariam em Temer para presidente da República: $2 \%$ responderam que sim... Dois dos ministros designados por Temer já tiveram de se demitir, depois da divulgação na imprensa de conversas em que justificavam a necessidade do golpe contra Dilma para frear as investigações da operação Lava Jato. (Lowy, p. 55)

O país em ebulição, todo um contexto político percorrendo nossos corpos. Submersa nesse caos que devastou e ainda aniquila todo o país, questionei infinitas vezes o que a pesquisa e criação em Artes Cênicas teria a ver com tudo isso. Com tantos retrocessos, como pensar e fazer teatro em tempos de espetacularização da política que forja múltiplas narrativas da realidade e utiliza estratégias de comunicação para persuadir a população de suas questionáveis invenções? Nesse contexto turbulento e cheio de mentiras fabricadas, penso que é necessário um teatro que olhe com o outro, que toque o outro, que se toque no outro. De qualquer modo, o teatro está em constante diálogo com a sociedade, propondo um olhar às outras pessoas e a articulação de um pensamento que se compõe em relação ao mundo. Parece que aproximações se fazem necessárias; muitos artistas têm trabalhado na esfera dos micro-espaços, das micro-ações e dos micro-diálogos. É esse tipo de teatro que me inspira.

A vida social e cotidiana interferiu diretamente no ser pesquisadora, ser artista, que entre tantos atravessamentos, se interessa pelas questões do teatro, das mulheres artistas e de como elas se colocam e escrevem suas histórias. Durante o processo de criação da montagem cênica Todas Nós ${ }^{5}$, questões de injustiças relacionadas às

\footnotetext{
${ }^{5}$ Equipe técnica: Elenco, sonorização e produção: lassanã Martins e Juçara Gaspar. lluminação: lassanã Martins. Dramaturgia e concepção do espetáculo: lassanã Martins, Juçara Gaspar e Patricia Fagundes. Colaboração artística: Patricia Fagundes.
} 
mulheres ecoavam em nossa sociedade e em mim. Foi em outubro de 2015 com a campanha \#PrimeiroAssedio ${ }^{6}$ - na qual diversas mulheres contaram episódios de suas vidas como forma de denunciar e combater o machismo e o sexismo - que o tema do espetáculo foi definido: Violência contra a Mulher. A dramaturgia foi composta a partir de casos de mulheres que sofreram e sofrem algum tipo de violência - doméstica, familiar, física, psicológica, institucional, etc. Outras narrativas foram reunidas a partir de livros, da internet, de relatos pessoais realizados na Delegacia Especializada de Atendimento à Mulher (DEAM) ${ }^{7}$ - lugar onde passamos ${ }^{8}$ uma semana conversando com mulheres vítimas de violência. Desde o princípio, foi uma opção contar histórias de mulheres anônimas no intuito de salientar a importância e a extensão do tema, demonstrando sua ocorrência, infelizmente, corriqueira na vida de tantas mulheres. Além de combinarmos relatos de outras pessoas com memórias das próprias atrizes. A escolha do tema e seu tratamento colaboraram na proximidade que eu buscava como atriz, operando na dimensão do sensível.

Ao escrever sobre o processo de criação comecei a questionar minha fala e meu modo de escrever, pois havia um certo distanciamento; era como se não estivesse escrevendo sobre o meu trabalho. Tanto no curso de graduação ${ }^{9}$ nas leituras sugeridas em aula, como nas leituras individuais como atriz em busca de conhecimento sobre meu ofício, sempre li e ouvi falar "trabalho do ator". Como aprendi dessa forma, continuei a falar e a escrever da mesma maneira. Já a palavra "homem", utilizada em textos colocando-o como ser universal, me causava um certo desconforto. No processo de escrita percebi que não fazia sentido escrever "o trabalho do ator" já que a equipe de trabalho era composta exclusivamente por mulheres.

Transferi essa falta de sentido do pensamento para o papel. Foi um processo trabalhoso, pois este tipo de escrita ainda é pouco habitual. Tampouco, isso é uma invenção minha. Sou influenciada por feministas que também questionam a escrita dominante, que coloca o homem como ser universal. Buscar outros modos de escrever é também provocar, enriquecer o diálogo e as possibilidades que inserem as mulheres nas histórias que estão sendo contadas. Após algumas tentativas que não facilitaram a fluidez do texto - como escrever o ator/atriz, espectador/espectadora por exemplo - a opção por escrever o memorial no feminino foi assumida, identificando a escrita com o teor do próprio trabalho. Em relação a esta ideia, Paula Cristina Ribeiro da Rocha de Morais Cunha ${ }^{10}$ (2012, p. 04), estudiosa na área de estudos de gênero afirma que

linguagem coloca-se para a mulher como uma questão de identidade, na medida em que, percebendo o mutismo a que foi, durante séculos, submetida, percebe também que o acesso às formas simbólicas da cultura e do poder se faz através

\footnotetext{
${ }^{6}$ Campanha virtual proposta pelo coletivo feminista Think Olga. Disponivel em: https://thinkolga.com/2015/10/26/hashtag-transformacao-82-mil-tweets-sobre-o-primeiroassediol. Acesso em: 30 de outubro de 2018.

${ }^{7} \mathrm{Na}$ cidade de Porto Alegre.

${ }^{8}$ Eu e minha parceira de cena, a atriz Juçara Gaspar.

${ }^{9}$ Graduação em Licenciatura em Teatro - Departamento de Arte Dramática da Universidade Federal do Rio Grande do Sul. Porto Alegre.

${ }^{10}$ Desenvolve atividades de docência em Literatura Portuguesa na Faculdade Sete de Setembro (FASETE). Em seu trabalho na área da literatura questiona a cultura dominante, mas também uma prática de leitura e análise da produção de autoria feminina. Tendo no centro do debate teórico a questão da diferença sexual e da existência de uma escrita feminina.
} 
da linguagem. Por isso, se as relações que o ser humano estabelece moldam a cultura, encarada, então, como produto histórico, então, necessariamente, as mulheres também têm um papel nessa construção.

Assim, o texto apresentado no memorial recusa o masculino universal, articulando uma escrita intencionalmente feminina, ou melhor, feminista. Pode-se dizer que, na norma culta, esse tipo de escrita é incorreto, mas quem faz a norma e quem diz que ela é culta? Em sua maioria homens, brancos e ricos.

\begin{abstract}
Não é demais reafirmar que os principais pontos da crítica feminista à ciência incidem na denúncia de seu caráter particularista, ideológico, racista e sexista: o saber ocidental opera no interior da lógica da identidade, valendo-se de categorias reflexivas, incapazes de pensar a diferença. Em outras palavras, atacam as feministas, os conceitos com que trabalham as Ciências Humanas são identitárias e, portanto, excludentes. Pensa-se a partir de um conceito universal de homem, que remete ao branco-heterossexualcivilizado-do-Primeiro-Mundo, deixando-se de lado todos aqueles que escapam deste modelo de referência. Da mesma forma, as práticas masculinas são mais valorizadas e hierarquizadas em relação às femininas, o mundo privado sendo considerado de menor importância frente à esfera pública, no imaginário ocidental. Portanto, as noções de objetividade e de neutralidade que garantiam a veracidade do conhecimento caem por terra, no mesmo movimento em que se denuncia o quanto os padrões de normatividade científica são impregnados por valores masculinos, raramente filóginos. (Rago, 1998, p. 4)
\end{abstract}

A historiadora Margareth Rago ${ }^{11}$ (1998) situa também a inserção e a visibilidade das mulheres nos espaços de pesquisa, operando diretamente no modo de registro que questiona a escrita até então "naturalizada". Em consonância com influências como esta, questiono e proponho uma escrita que inicialmente causa certo estranhamento, visto que, quando escrevo "o trabalho da atriz", "as espectadoras", "as outras" e todas as demais palavras no feminino, me refiro tanto às mulheres quanto aos homens, subvertendo o denominador universal hegemônico. Uma escrita que também se propõe como exercício político.

\title{
Mulheres da cena
}

Escrever, pensar a cena, imaginar um teatro construído por tantos homens. Assim somos conduzidas no percurso de nossa formação teatral: a pensar nos grandes homens do teatro. Aprendemos a admirá-los pela sua dedicação e pela sua paixão por esse ofício. Mas e as grandes mulheres do teatro? Ao olhar para minha própria trajetória, percebi que conhecia poucas mulheres na história do teatro, se comparado aos registros de homens de teatro. Já em minha trajetória como estudante de teatro, minhas maiores referências e inspirações são mulheres: professoras, diretoras, atrizes, iluminadoras, produtoras e técnicas. Mulheres que influenciam diretamente minhas escolhas profissionais, afirmando que seus discursos sobre a cena importam e compõem a narrativa da história do teatro.

\footnotetext{
${ }^{11}$ Docente titular do Departamento de História da Universidade Estadual de Campinas (UNICAMP). Importante pesquisadora em questões de gênero. É co-editora da Revista Aulas, da Linha de Pesquisa Gênero, Subjetividades e Cultura Material do PPGRH da UNICAMP. Áreas de ensino e pesquisa: Teoria da História e História do Brasil República; pós-estruturalismo, feminismos, anarquismos, subjetividade, gênero. Autora de diversos livros como: Os Prazeres da Noite. Prostituição e códigos da sexualidade feminina em São Paulo, 1890-1930. A aventura de contar-se: feminismos, escrita de si e invenções da subjetividade (Editora da UNICAMP, 2013).
} 
Essa inquietação surgiu na pesquisa atravessada pelo momento histórico em que vivemos, onde as mulheres exigem seu lugar de fala, de escrita, de reconhecimento, de pertencimento e de direito a viver como bem compreendem. Reconheço esse momento como uma conquista de diversas mulheres ao longo dos anos. Tanto das mulheres reconhecidas na história do feminismo como daquelas que foram apagadas nesses anos de luta e de enfrentamento. Influenciada por esse modo de pensar, a escrita se concretizou a partir de um corpo motivado pelo pensamento de muitas mulheres, artistas, feministas. Nessa trajetória, nasceu o desejo de escrever sobre mulheres artistas da cena que de alguma maneira influenciam o meu trabalho, sejam mulheres que estão em cena comigo, que habitam em minha cidade, meu país, outros lugares do mundo, outros lugares no tempo. Artistas que compõem minha história e a história do teatro.

Cacilda Becker e Cleyde Yáconis, atrizes que compartilharam outro tempo e que tiveram uma longa e importante trajetória no teatro brasileiro; Bibi Ferreira, atriz, cantora, compositora que atuou até seus 96 anos; Juliana Carneiro da Cunha, atriz brasileira integrante do grupo francês Théâtre du Soleil; Arlete Cunha, atriz Porto Alegrense, reconhecida na cidade como uma grande e importante atriz, que voltou a atuar há poucos anos, e que tenho o privilégio de poder confirmar, ao vê-la em cena, o que estava em meu imaginário; Grace Passô, que como muitas artistas ocupa diversas funções - atriz, dramaturga, encenadora. Entre essas artistas, algumas que conheço pessoalmente, que vi em cena, que conheci através de registros em livros ou vídeos, estão muitas outras que citarei em seguida sem a pretensão de esgotar o arsenal de referências possíveis, mas principalmente com o intuito de registrar esses nomes:

Carolina Virguez, Celina Alcântara, Patricia Soso, Maria Della Costa, Sandra Dani, Liane Venturella, Aline Marques, Gabriela Poester, Elisa Lucinda, Roberta Estrela D'Alva, Thais Araújo, Aracy Esteves, Inês Peixoto, Ligia Rigo, Claudia de Bem, Isabelle Huppert, Marieta Severo, Ascendina dos Santos, Patricia Fagundes, Leila Diniz, Denise Fraga, Mônica Dantas, Gabriela Greco, Gisela Habeyche, Sandra Possani, Inês Marocco, Ruth de Sousa, Ariane Mnouchkine, Naomi Silman, Daniela Aquino, Pâmela Amaro, Simone Ordones, Jacqueline Pinzon, Roberta de Savian, Fernanda Vianna, Tânia Farias, Diana Manenti, Adriane Mottola, Lorena Sanchez, Leticia Paranhos, Lydia del Picchia, Fernanda Carvalho Leite, Juçara Gaspar, Béthany Martinez, Kaya Rodrigues, Gabriela Chultz, Camila Mota, Carol Zimmer, Tefa Polidoro, Mônica Blume, Maíra Prates, Fernanda Bertoncelo Boff, Bruna Immich, Valquiria Cardoso, Laura Backes, Priscila Morais, Manoela Miranda, Sylvia Prado, Wanda Fernandes, Zica Stockmans, Else Marie Laukvik, Priscila Colombi, Iben Nagel Rasmussen, Sissi Venturin, Ana Cristina Colla, Julia Varley, Ângela Gonzaga, Jezebel De Carli, Janaina Kremer, Mirna Spritzer, Juliana Kersting, Anne Bogart, Maria Helena Lopes, Ana Zanandréa, Dedy Ricardo, Irene Brietzke, Ana Fuchs, Dudude, Fernanda Montenegro, Janaina Leite, Guadalupe Casal, Maria Alice Vergueiro, Mirna Spritzer, Roberta Carreri, Camila Falcão, Priscila Padilha, Tatiana Cardoso, Dani Dutra, Carina Sehn, Teuda Barra, Mariana Rosa, Camila Bauer, Vitória Monteiro, Thais Fernandes, Ana Cláudia Bernareki, Camila Bastos Bacellar, Paola Vasconcelos, Renata Teixeira, Mirah Laline, Julia Rodrigues, Carolina Garcia...

Estas então são algumas das mulheres artistas que fazem da cena seu lugar de fala. "Ao promover uma multiplicidade de vozes o que se quer, acima de tudo, é quebrar com o discurso autorizado e único, que se pretende universal" (Ribeiro, 2018, p. 70). Neste sentido a noção de "lugar de fala", tão discutida nos últimos tempos, evidencia a condição social-individual de quem articula narrativas, desconstruindo a 
possibilidade de imparcialidade ou universalidade. Artistas que ao falarem de si falam de outras e compõem meu repertório. E repertório é uma ferramenta fundamental no trabalho de uma artista, pois criamos a partir de um arquivo de possibilidades, de um painel de referências que abriga conceitos, práticas, propostas artísticas, discursos, procedimentos desenvolvidos por outras pessoas, grupos, movimentos, além de nós. Esse repertório que nos compõe inclui experiências da vida mesma, tanto da nossa como das pessoas que nos inspiram.

O teatro também pode ser pensado como um lugar de fala. Muitas atrizes e performers encontraram modos de levar à cena histórias biográficas e autobiográficas questionando, denunciando os discursos dominantes que se impunham sobre seus corpos, sobre suas vidas. "Não se trata simplesmente de termos 'diversidade em cena' nem de abordar esse apagamento como 'conteúdo'. [...] têm sim a ver com como levamos o que levamos para a cena" (Bacellar, 2017, p. 27).

Marvin Carlson ${ }^{12}$ (2010, p. 169), contextualiza as performances desenvolvidas durante os anos de 1970 e de 1980 por artistas que levavam à cena questões autobiográficas e experiências pessoais, considerando o procedimento como "a mais típica orientação da performance feminista".

As mulheres também foram atraídas para a performance porque ela lhes permitia o controle pessoal. Diferentemente dos atores tradicionais, elas criaram seus próprios projetos - servindo como escritoras, produtoras, diretoras, desenhistas, elenco e, muitas vezes, também carpinteiras e figurinistas (Ibidem, p. 168).

Carlson (2010) considera que os homens artistas que dominavam as performances e os filmes experimentais no final dos anos de 1970 não eram simpáticos aos trabalhos preocupados com a autoimagem, o self e o eu social, enquanto essas eram preocupações centrais das artistas mulheres do mesmo período. O autor descreve várias performances desenvolvidas na época por mulheres nos Estados Unidos, dentre as quais destaco cinco: i) em 1968, a performance Mitchell's Death ["A morte de Mitchell"], de Linda Montano, ocupava-se da perda de seu ex-marido e amigo Mitchell Payne; ii) no ano seguinte (1969), Barbara Smith ${ }^{13}$ performava sobre a morte de sua mãe, explorando seus sentimentos e suas observações em torno do assunto; iii) em 1973, com a obra The History of My Life [A história da minha vida], recitando sua autobiografia num sistema de amplificação, Linda Montano realizou a performance subindo, durante três horas, uma montanha em uma esteira; iv) no mesmo ano, Yvone Rainer compôs uma performance juntando material autobiográfico e ficção, em This is History of a Woman Who... [Esta é a história da mulher que...], que, mais tarde, foi transformado em um grande filme feminista14; e v) Woman and Violence [Mulheres e Violência], de 1976, trabalho desenvolvido com material autobiográfico e histórico pelo grupo Spiderwoman ${ }^{15}$.

\footnotetext{
${ }^{12}$ Professor de Teatro e Literatura Comparada no Centro de Graduação da Universidade da Cidade de Nova lorque, nos Estados Unidos. Doutor honoris causa pela Universidade de Atenas.

${ }^{13}$ Marvin Carlson não cita o nome da performance em seu texto.

${ }^{14}$ Disponivel em https://www.youtube.com/watch?v=LBOBQxZ12Dk Acesso em: 27 fev. 2017.

${ }^{15}$ Spiderwoman Theater é a mais antiga companhia de teatro de mulheres indígenas em operação contínua das Américas. Sua obra aborda questões culturais, sociais e políticas que afetam as comunidades indígenas e as mulheres. Através da técnica de "tecelagem de estórias", criam suas produções e realizam suas atividades de treinamento e de sensibilização". Texto disponivel em: http://hemisphericinstitute.org/hemi/pt/enc14-performances/item/2351-enc14-performances-spiderwoman-mother. Acesso em: 30 de outubro de 2018.
} 
Em outro contexto, a cena feminista atual também se desenvolve sobre aspectos de extrema urgência, sobretudo em relação ao corpo, ao social e ao político. Embora reconheçamos que a situação social das mulheres melhorou em alguns pontos, essa melhora ainda é categoricamente insuficiente. Como diz a encenadora Ariane Mnouchkine $^{16}$ (2011), "[...] a luta das mulheres é a mais urgente das lutas. Enquanto elas não tiverem as leis a seu favor, as terão contra elas" (p. 109). Dito isso, destaco a seguir quatro espetáculos, de artistas mulheres que, além de colaborarem na construção de um pensamento sobre o trabalho de atuação em diálogo com aspectos biográficos e autobiográficos, fazem da cena um lugar político e poético.

\section{Cena e escrita: uma narrativa contada por mulheres}

Em 2010, em seu Estágio de Atuação II ${ }^{17}$, Stefanie Polidoro ${ }^{18}$ tece um trabalho a partir da história de sua mãe, uma mulher que criou sua filha sozinha e esperou durante anos por notícias do marido que viajou. No espetáculo (E)terno ${ }^{19}$, a história da mãe, que é também a história de tantas mulheres, foi inspiração para o trabalho da filha artista. Anos depois, Tefa Polidoro realizou seu mestrado em processos composicionais cênicos feministas pela Universidade Estadual de Santa Catarina. Em sua dissertação, Tefa fala sobre a importância de seu Estágio de Atuação:

Percebi, a partir de (E)terno, o trabalho que desenvolvi na minha graduação, que o teatro poderia ser um meio bastante eficaz para visibilizar e questionar algumas visões a respeito de mulheres rechaçadas ou escondidas por interesses quaisquer: ou porque mancharam a história de alguma família, ou porque não contribuíram para a formação cultural ou financeira de algum local, ou porque destoram de alguma realidade vigente. Ou simplesmente por serem mulheres. (Polidoro, 2016, p. 38)

O espetáculo Umas e outras - O Feminino pela Ótica do Circo Expandido ${ }^{20}$ (2016), do qual sou iluminadora, também desenvolve questões sobre a mulher, mais especificamente sobre violência de gênero. Antes mesmo de compor a equipe, acompanhei a fase inicial de criação, quando as performers Ana Bernarecki e Bethany Martínez se ocupavam de exercícios e de improvisações a partir do livro Mulheres que Correm com Lobos, de Clarissa Pinkola Estés (1994). Gradualmente, a equipe foi crescendo, a montagem foi tomando outras proporções e modificando-se ao longo do processo. A convite do grupo, fiz meu primeiro trabalho como iluminadora. O espetáculo valoriza histórias biográficas de diversas mulheres "enfocando momentos resultantes de

\footnotetext{
${ }^{16}$ Diretora do Théâtre du Soleil, Paris - França.

${ }^{17}$ Estágio realizado no Departamento de Arte Dramática de Universidade Federal do Rio Grande do Sul.

${ }^{18}$ Nome artístico Tefa Polidoro. Doutoranda pela Universidade Estadual de Santa Catarina (UDESC).

${ }^{19}$ Mostra DAD. Ficha técnica: Orientação: Luciane Olendski; Direção: Márcio Ramos; Atuação: Tefa Polidoro; Textos: Luciane Olendzki e Tefa Polidoro; Sonoplastias e trilha sonora: Franciele Duarte e Rafael Salib; Produção audiovisual: Generall Vídeos; Financiamento: Prêmio de Incentivo à Montagem Teatral de Caxias do Sul/2010. Disponível em http://mostradad.blogspot.com.br/2010/11/ Acesso em: 18 jul. 2017.

${ }^{20}$ Ficha Técnica: Performance e concepção: Ana Bernarecki e Bethany Martínez; Câmera e Performance ao vivo: Ana Girardello; Direção: Jacqueline Pinzon; lluminação: [...]; Sonoplastia e contraregragem: Lorena Sanchez; Figurinos: Clarissa Marchetti; Ambientação e Trilha: 0 Grupo; Projeções: Jacqueline Pinzon , Maurício Casiraghi e Ana Girardello; Fotografia: Aline More; Teaser: Natalia Utz; Arte gráfica: Manifesto Comunicação; Produção: Ana Bernarecki e Lorena Sanchez; Realização: Brio Arte Movimento.
} 
abusos, violência e preconceitos dos quais a mulher frequentemente é alvo na sociedade" (folder de divulgação do espetáculo ${ }^{21}, \mathrm{~s} / \mathrm{p}$ ). Na interlocução entre circo, dança e teatro, Umas e outras expõe em cena um tema de inegável relevância social.

Em 2011, assisti duas vezes ${ }^{22}$ ao espetáculo Viver Sem Tempos Mortos ${ }^{23}$ (2009), com atuação de Fernanda Montenegro. Antes da atriz entrar em cena, pensei: "Poxa, eu não vou conseguir prestar atenção, tô muito nervosa!". Em seguida, Fernanda entrou, sentou-se na cadeira exatamente em frente à minha e lá ficou durante, aproximadamente, uma hora. Uma atriz, uma cadeira, um facho de luz, um mundo todo. A combinação entre Fernanda Montenegro e a produção literária de Simone De Beauvoir me fascinava. Lembro-me que tentava distinguir o que era da atriz e o que era da escritora, pois a dramaturgia da peça mesclava histórias das duas mulheres. "Quando você pega um personagem com temperamento rico como o de Simone e fala de sua biografia, você relaciona com a sua trajetória. A peça é uma revisão da minha vida [...]"24. Em uma reportagem em homenagem aos seus 80 anos, Fernanda Montenegro recita parte de um texto de Simone De Beauvoir:

A impressão que eu tenho é de não ter envelhecido, embora eu esteja instalada na velhice. O tempo é irrealizável. Provisoriamente, o tempo parou pra mim. Provisoriamente. Mas eu não ignoro as ameaças que o futuro encerra, como também não ignoro que é o meu passado que define a minha abertura para o futuro. $\mathrm{O}$ meu passado é a referência que me projeta e que eu devo ultrapassar. Portanto, ao meu passado, eu devo o meu saber e a minha ignorância, as minhas necessidades, as minhas relações, a minha cultura e o meu corpo. Que espaço o meu passado deixa pra minha liberdade hoje? Não sou escrava dele. O que eu sempre quis foi comunicar da maneira mais direta o sabor da minha vida, unicamente o sabor da minha vida. Acho que eu consegui fazê-lo. Vivi num mundo de homens guardando em mim o melhor da minha feminilidade. Não desejei nem desejo nada mais do que viver sem tempos mortos. ${ }^{25}$

Fernanda complementa: "Acho que aí seria o momento da encenação que eu assinaria em baixo e que eu não vou ficar aqui repetindo minhas palavras, se eu encontrei este trecho tão profundo e tão verdadeiro de uma mulher que sabe dizer isto melhor do que eu". Assim como Fernanda Montenegro encontrou nas palavras de Beauvoir dizeres que narram sua vida, Maria Alice Vergueiro leva à cena suas próprias referencias. Como artistas, ao falar da vida, falamos da nossa própria vida.

O espetáculo Why the horse? (2015) trata da biografia da atriz Maria Alice Vergueiro, que concebeu a montagem a partir de uma experiência muito próxima à morte, o que a levou a querer saber como seria o seu último encontro.

\footnotetext{
${ }^{21}$ Trecho extraído da sinopse do espetáculo disponível em https://www.facebook.com/Brio-Arte-e-movimento-231827973886879/ Acesso em 15 de julho de 2017.

${ }^{22}$ Em agosto de 2011, no Theatro São Pedro, em Porto Alegre/RS, e em outubro do mesmo ano, no Teatro Raul Cortez, em São Paulo/SP.

${ }^{23}$ Ficha técnica: Texto: a partir das correspondências de Simone de Beauvoir para Jean-Paul Sartre; Elenco: Fernanda Montenegro; Direção: Felipe Hirsch. Tao Produções Ltda., Bonarcado Produções Artísticas Ltda., Arlete Pinheiro Monteiro Torres, Trígonos Produções Culturais Ltda., Carmen Lúcia de Melo Silva.

${ }^{24}$ Fernanda Montenegro em entrevista cedida a Guilherme Udor. (2012). Disponivel em https://www.guiadasemana.com.br/arte/noticia/fernanda-montenegro-vive-simonede-beauvoir Acesso em 20 de julho de 2017.

${ }^{25}$ Transcrição minha de trecho da entrevista cedida por Fernanda Montenegro à Globo News. (2012). Disponivel em https://www.youtube.com/watch?v=4gcBeOqNdpU Acesso em: 20 jul.2017.
} 
Instigada pelo tema da morte e reconhecendo seu próprio e natural receio diante do fim, bem como a força artística que envolve, Maria Alice Vergueiro convocou seus parceiros do Grupo Pândega para a criação de um espetáculo em que pudesse ensaiar seu derradeiro momento. Um último ensaio, um mergulho nesta temática ao mesmo tempo tão pessoal e universal, cerne do imaginário grotesco. Aos 80 anos e mais de 50 de palco, Maria Alice não pensa em parar. Em suas palavras, sempre um pouco irreverentes: 'Quero ensaiar a morte para não ser pega de surpresa. Com sorte, pode ser que eu morra em cena. Se não, estaremos de volta no dia seguinte' ${ }^{26}$

Antes da atriz entrar em cena, o público pode observar o cenário composto por lápides com nomes de artistas da literatura e do teatro que foram inspirações em sua trajetória, como Bertolt Brecht, Franz Kafka, Cacilda Becker e Augusto Boal. Maria Alice atravessa lentamente o palco, com ajuda de uma atriz, é acompanhada até chegar em sua cadeira de rodas. Nos mostra sua dificuldade em andar e falar devido a doença de Parkinson e por ter sofrido um derrame. Um corpo real que se coloca com suas dificuldades diante dos olhos das espectadoras que "não perceberam [a atriz] como signo de uma figura particular, mas unicamente como seu estar-no-mundo em sua corporeidade própria" (Fischer-Lichte, 2014, p. 17). Percebemos sua fragilidade. Ela é real. Causa um certo impacto, nos comove.

Impactada, ao chegar em casa escrevi:

Why the horse? Why the horse? Porque sim. Porque pode cavalo, pode se fazer referência às próprias referências em suas lápides, pode fazer uma ode ao teatro, pode fazer referência à vida e à morte. Maria Alice Vergueiro ensaia seu próprio velório, entra em cena na própria presença, na grandiosidade que é ser e estar no aqui e agora, dividindo com outros a angústia de ensaiar seu próprio velório. Propõe um teatro que a expõe em todos os sentidos, sua vulnerabilidade rasgada, tremida, cantada. Um sonho vomitado, sujo, molhado, enfeitiçado, poetizado ${ }^{27}$

A cada ensaio de morte, uma vida pulsante. Em cena, a sua vida, o seu poético modo de escutar e de falar. "Falar é também se falar" (Wulf, 2007, p. 02). Um espetáculo marcado pela história da atriz, pela sua visão e pela sua experiência de proximidade com a morte. Não há a interpretação de outrem; apenas daquele próprio corpo-memória de Maria Alice. Borram-se as fronteiras entre real e ficcional. Afirma-se o real que transborda do palco e conecta-se às nossas próprias experiências de mortalidade. Por outro lado, diversos elementos estéticos, que beiram, algumas vezes, ao nonsense, nos convidam à dimensão ficcional, assim como a própria escolha do texto - ora na primeira pessoa do singular, ora improvisado, ora cantado - e como as intervenções das colegas de cena de Maria Alice, as quais transitam entre personagens.

A peça termina com a atriz deitada, com um véu cobrindo o seu corpo. Silêncio póstumo. Há um aspecto sobre este espetáculo que considero importante destacar: a necessidade de uma atriz de 81 anos falar sobre a morte, evidenciando e nos provocando a pensar questões sobre a velhice. Vivemos numa sociedade de urgências, onde não há tempo para pensar na vida, muito menos na morte. Compramos a ideia

\footnotetext{
${ }^{26}$ Sinopse do espetáculo Why the Horse? disponível em http://www.sesc.com.br/portal/site/palcogiratorio/2016/espetaculos/grupopandegadeteatro/espetaculo38?grupo=espetaculo38 Acesso em: 03 jul. 2016.

${ }^{27}$ Anotação pessoal da atriz.
} 
de sermos sempre jovens e fortes. Desse modo, a lentidão do caminhar dos idosos torna-se inconcebível e, portanto, esquecida. Maria Alice Vergueiro faz o contrário: toma o seu tempo e, diante dos nossos olhos, torna a vida mais profunda, mais densa. A atriz faz das suas questões pessoais uma questão ética e política. A experiência de vida da atriz transforma-se em poesia.

Os dois últimos espetáculos mencionados tratam do tempo, da morte e da velhice. O tempo como algo que nos fascina, que nos escapa; a morte, em nossa sociedade, fica na esfera do indizível: não sabemos como lidar com a única certeza que temos; já a velhice, principalmente para a mulher, se mostra sempre cruel: o corpo sendo controlado por padrões de beleza e de juventude a serviço de uma indústria. Enquanto incentiva-se as mulheres a cobrirem os cabelos brancos, a inserirem botox para esticar a pele, a deixarem de usar roupas que julgam não adequadas para a idade, libera-se os homens dessas obrigações, já que eles podem ser calvos, seus cabelos grisalhos são reconhecidos, muitas vezes, como charme, podem namorar garotas consideravelmente mais novas. Por outro lado, as mulheres são alvo constante de críticas e julgamentos em uma sociedade patriarcal, especialmente quando são mais velhas. Fernanda Montenegro e Maria Alice Vergueiro são atrizes que fazem da cena um lugar de manifesto e mostram que suas experiências transgridem padrões.

Mulheres que criam, que tecem suas histórias na cena, na vida, que estabelecem relações com a criação cênica e com a escrita. É preciso propor uma reflexão crítica sobre as estruturas que se apresentam naturalizadas e que inserem um jeito específico de pensar e de narrar. Narrativas que compõem todos os campos, inclusive o do teatro. Por isso, este texto é um convite para pensarmos a maneira como contamos e articulamos a história do teatro, que se evidencia a partir dos grandes homens do teatro, sendo que ela também é composta por muitas mulheres que estão, desde muito tempo, inseridas nas mais diversas funções. Por isso, a importância de apresentar criações cênicas desenvolvidas sob a perspectiva de artistas que fizeram ou fazem a cena a partir de suas próprias experiências, as quais vão muito além de histórias particulares. Pelo contrário: suas narrativas servem como forma de identificação para muitas pessoas e como reconhecimento da alteridade. Principalmente ao pensarmos no momento social e político no qual estamos inseridas, influenciando diretamente no modo de criar na cena e na escrita. O tempo atravessando este corpo, se fazendo narrativa no mundo. Escrever como atriz, como mulher. Uma escrita feminista que se reconhece como ato político.

\section{Referências}

BACELLAR, Camila Bastos; LEAL, Mara Lucia; ALCURE, Adriana Schneider; AZEVEDO, Maria Thereza. Pedagogias Feministas e de(s)coloniais nas artes da vida. Ouvirouver. Uberlândia v. 13 n. 1, 2017.

CARLSON, Marvin. Performance uma introdução crítica. Belo Horizonte: UFMG, 2010.

CORNAGO, Óscar. A veces me pregunto por qué sigo bailando: Prácticas de la intimidad. Madrid: Editorial Continta me tienes, colección Escénicas, octubre 2011. 
CLETO, Murilo; DORIA, Kim; JINKINGS, Ivana (Orgs.). Por que gritamos Golpe? Para entender o impeachment e a crise política no Brasil. São Paulo: Ed. Boitempo, 2016.

CUNHA, Paula Cristina Ribeiro da Rocha de Morais. "Da crítica feminista e a escrita feminina". In: Revista Criação \& Crítica. São Paulo. n. 8, 2012. p. 1-11. Disponível em http://www.revistas.usp.br/criacaoecritica/article/view/46837/50598. Acesso em 22 de julho de 2016.

ESTÉS, Clarissa Pinkola. Mulheres que correm com os lobos. Rio de Janeiro, Rocco, 1994.

FISCHER-LICHTE, Erika. Estética de lo performativo. Madrid: Abada Editora, 2014.

MNOUCHKINE, Ariane. A arte do presente; entrevistas com Fabienne Pascaud. Rio de Janeiro: Cobogó, 2011.

POLIDORO. Stefanie Liz. Pílula da Visibilidade: Maria Scariot Presente! O processo criativo e feminista de Due Lati Della Campana. Dissertação de mestrado. Orientadora: Maria Brígida de Miranda. Universidade de Santa Catarina, Programa de Pós-Graduação em Teatro, 2016.

RAGO. Margareth. "Epistemologia feminista, gênero e história”. In: PEDRO, Joana; GROSSI, Miriam (Orgs.). Masculino, Feminino, Plural. Florianópolis: Ed. Mulheres, 1998. p. 316-329.

RIBEIRO, Djamila. O que é lugar de fala?. Belo Horizonte (MG): Letramento: 2017.

WULF, Cristoph. "O ouvido". In: Ghrebh, Revista de comunicação, cultura e teoria da mídia. São Paulo: n.9, março de 2007. p. 56-67.

\section{Espetáculos}

MONTANO, Linda. Mitchell's Death. 1968. . The History of My Life. 1973.

MONTENEGRO, Fernanda. Viver sem Tempos Mortos. Espetáculo assistido em Porto Alegre, agosto de 2011.

MOVIMENTO, Brio Arte. Umas e outras - O Feminino pela Ótica do Circo Expandido. Espetáculo assistido em Porto Alegre, março de 2017.

PÂNDEGA, Grupo e VERGUEIRO, Alice. Why the horse?. Espetáculo assistido em Porto Alegre, maio de 2016. Disponível em https://grupopandega.wordpress.com/ why-the-horse-o-ultimo-ensaio/ Acesso em 03 de julho de 2016. 
POLIDORO, Stefanie Liz. (E)terno. Espetáculo assistido em Porto Alegre, dezembro de 2010.

RAINER, Yvone Rainer. This is History of a Woman Who..., 1973.

SPIDERWOMAN. Group. Woman and Violence. Cidade, 1976.

Recebido em: 30/09/2018 Aprovado em: 04/11/2018 